\title{
Fostering Undergraduate Students' Creativity via the Training of Advanced Technologies
}

\author{
Deng-Guang Yu \\ School of Materials Science \& Engineering, University of Shanghai for Science and Technology, Shanghai 200093, China \\ ydg017@usst.edu.cn, feiyu.dpan@gmail.com
}

\begin{abstract}
The teaching in higher education should pay more attention to nurture the undergraduate students' creativity. Advanced technologies could act as a fine platform to foster creative learning and innovative teaching. An experiment of a short time period training using three types of up-to-date technologies (3-D printing, electrospinning and electrospraying) on the students was carried out. The effects of this training on the students creative leaning and thinking are analyzed. It is recommended that increased practical courses about advanced technologies should be arranged for the undergraduate students to undertake all-around training for nurturing innovative brains.
\end{abstract}

Index Terms - Higher education, Undergraduate student, Advanced technologies, Creativity

\section{Introduction}

This world would have no advancement in art, literature, science, and invention if human creativity did not exist. Creativity and innovation are becoming more and more important for the development of the knowledge society. They contribute to economic prosperity as well as to social and individual wellbeing and are essential factors for a more competitive group. Education is seen as central in fostering creative and innovative brains [1]. Anderson (1990) has explored the importance of creativity in higher education by advocating that the college experience should include an opportunity to discover one's potential and achieve higher levels of creative expression. It can be argued that the extent to which this happens depends on curriculum design and the commitment of teachers to nurture this development in the colleges or universities [2].

Higher education is an optional final stage of formal learning that occurs after secondary education. Higher education should include teaching, research, exacting applied work (e.g. in medical schools), and social services activities of universities. Creativity in higher education often has more to do with the process than with the product, and focuses therefore on the development of thinking, cooperating and cognitive skills [3]. To some extent, higher education is a bridge between "passive learning" from teachers and teaching materials to "active learning" from practices, working or academic researches. "Genuine knowledge comes from practice" as said by Ze-Dong Mao, more and more practical courses should be arranged for the undergraduate students from the college freshmen to senior students.

Technologies play a crucial role in our lives and can enable educational change towards an innovative and creative school environment in our modern society. They are explored to produce numerous commercial products. They can also act as a platform to foster creative learning and innovative teaching and are currently offering a variety of opportunities for constructive change of knowledge, just as computer and internet that have brought extremely large changes to the higher educations.

Accordingly, both teachers and undergraduate students in higher schools should acquire the critical skills in their use of technologies to be able to benefit from them in an effective, innovative and creative way. Educational systems should also take into account the empowerment culture brought about by new technologies, putting the students at the centre of the learning process. Otherwise, there is the risk that education policies and systems become irrelevant for students' real and future needs.

Teachers in higher education are still playing important roles to enhance any components of students' creativity as the primary and middle school [4]. Teachers not only need to have the required knowledge to be able to identify creative and innovative skills and processes amongst their students. They also need to be trained in the advanced but fundamental fields, keep up with rapid technological developments, and for the better grasp several advanced technologies.

The paper argue that advanced technologies can provide a fine tool for the teachers in higher education for fostering the undergraduate students' creativity, a nice platform for the students to thinking and learning. And our experiments of training of three up-to-date technologies (three-dimensional printing or 3D-printing, electrospinning and electrospraying) on undergraduate students can provide good learning environments for the students, motivating their enthusiasms for creative thinking.

\section{Several Advanced Technologies}

Today's world, described as a knowledge society and an information age, poses challenges for higher educational institutions and their teachers. Ironically, educators sometimes teach students about new products, creative and eminent people, and fast development of the society, but ignore teaching that fosters students' creative thinking in their courses. Sometimes, they maybe just lack suitable materials to provoke the creative thinking. Here, we list three advanced technologies that are explored for the training of undergraduate students in our university.

3D-printing is a new rapid prototyping technique. The system was first developed at the Massachusetts Institute of 
Technology in 1992. Based on computer-aided design (CAD) models and manipulated by a terminal computer, 3D-printing constructs parts in a very simple layer-wise manner rapidly. A typical process is shown in Fig. 1a. A layer of powder is spread onto the powder-bed on which the prototype is to be created. A print head, similar to that used in ink printing, is driven by an $X-Y$ orientation system to eject a binding materials onto the powder to produce the base layer according to the specified CAD pattern. The powder-bed, driven by the piston rod in the $Z$ vertical orientation, is then lowered by a pre-determined layer thickness and the process is repeated until the required $3 \mathrm{D}$ shape has been produced. After treatment, unbound powder is removed, leaving the fabricated part [5].
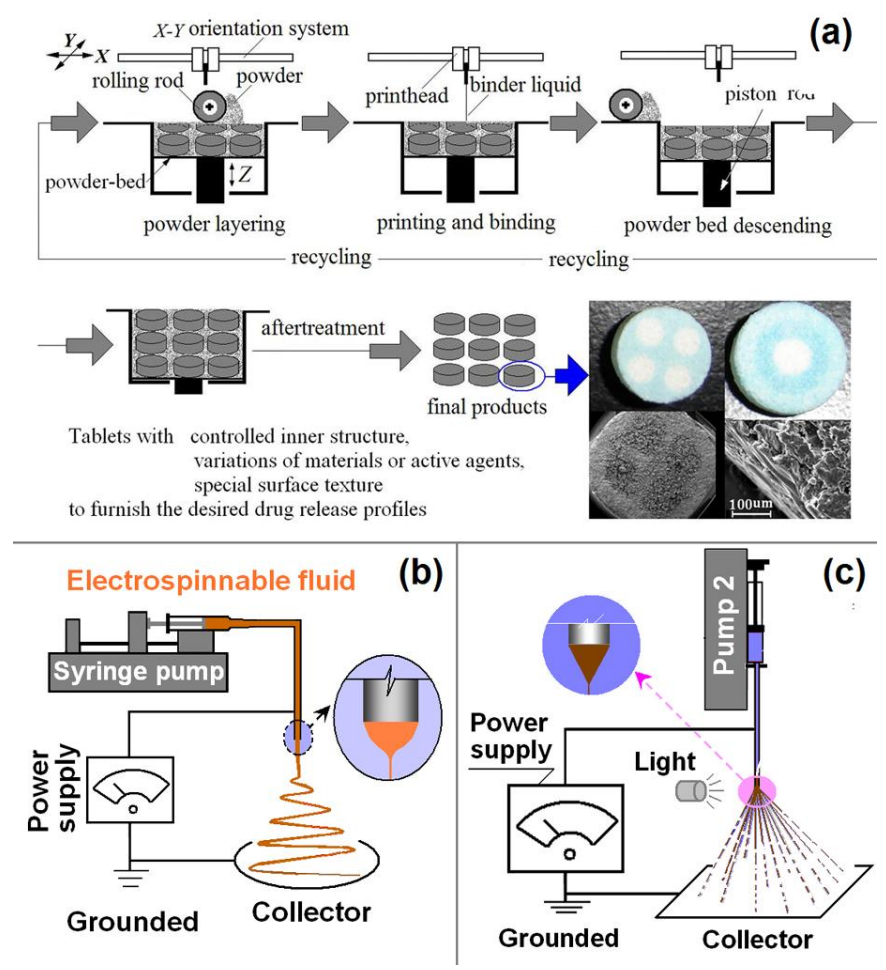

Fig. 1 Schematic diagrams of the three types of advanced technologies: a) Three-dimensional printing; b) Electrospinning; c) Electrospraying

Electrospinning uses an electrical charge to draw very fine (typically on the micro or nano scale) fibers from a liquid (Fig. 1b). Electrospinning shares characteristics of both electrospraying and conventional solution dry spinning of fibers. The process is non-invasive and does not require the use of coagulation chemistry or high temperatures to produce solid threads from solution. This makes the process particularly suited to the production of fibers using large and complex molecules. When a sufficiently high voltage is applied to a liquid droplet, the body of the liquid becomes charged, and electrostatic repulsion counteracts the surface tension and droplet is stretched, at a critical point a stream of liquid erupts from the surface. This point of eruption is known as the Taylor cone. If the molecular cohesion of the liquid is sufficiently high, stream breakup does not occur and a charged liquid jet is formed. As the jet dries in flight, the mode of current flow changes from ohmic to convective as the charge migrates to the surface of the fiber. The jet is then elongated by a whipping process caused by electrostatic repulsion initiated at small bends in the fiber, until it is finally deposited on the grounded collector. The elongation and thinning of the fiber resulting from this bending instability leads to the formation of uniform fibers with nanometer-scale diameters [6].

A schematic electrospraying system is illustrated in Fig. 1c. During the electrospraying process, a liquid is fed to a metal capillary at the end of which a droplet is formed. When the droplet is exposed to a strong electrical field, a charge is induced on its surface. Provided the liquid has sufficient electrical conductivity, there will be a range of combinations of the liquid flow rate and the applied voltage for which the drop will assume a conical shape (the Taylor cone). At the apex of this cone, a narrow jet is formed (cone-jet mode) which subsequently breaks up into fine droplets [7].

\section{Advanced technologies - a better platform for higher education}

Scardamalia emphasizes developing skills for lifelong learning. These skills are associated with teaching methods which encourage students to take more active roles in learning, less so with methods based on knowledge transmission [8]. Technology could act as a platform to foster creative learning and innovative teaching. Compared with the traditional classroom lessons, some advantages of the training of advanced technologies are listed as follows:

First of all, the training of advanced technologies to the undergraduate students' courses is up-to-date. In china, the Chinese Ministry of Education once advocated the combination of Medical and Engineering, advocated the interdisciplinary research, now it encourages collaborative innovation. The lessons about advanced technologies can provide an all-around training for the students to improve their ability, creativity, expand their kens, and provide a series of stimuli to provoke their interesting to skills and knowledge.

Second, the training of advanced technologies to the undergraduate students can provide a creative environment for the students to share the teachers' experience on modern science and technologies, promoting the face-to-face knowledge transmission. Particularly, many higher education institutions in China are still primarily relying on traditional platforms such as course and learning management systems that do not capitalize on the pedagogical affordances of advanced technologies [9]. The practical lessons about advanced technologies should bring out new atmosphere for the students to learning and thinking.

Third, a practical training of advanced technologies would allow the students to manage and maintain a learning space that facilitates their own learning activities and connections to peers. The approach and even grasp of advanced technologies should benefit both the students in higher academic education and those in higher vocational 
education. The students not only learn about creativity by focusing on the work of others but they can achieve brand-new experience about the material transitions during the implementation of advanced technologies.

Forth, the practical training of advanced technologies can improve the students' habit for construction of knowledge, which is an important element for the development of creativity for the students. The advanced technologies lessons should create the right motivational climate for learning, providing a lot of chances for the students to recall their prior knowledge and meanwhile furnishing many hints to think about new knowledge. Learning is just a creative process that involves students making information relevant by linking prior knowledge and new knowledge in an individually meaningful format [10].

Certainly, during the training process, the student could not help thinking how to break through barriers, generate ideas, identify opportunities, make judgments, and alter experiments, use trial and error. All of this is exercising creativity because, as human beings, the undergraduate students are creative beings.

\section{Inspiring the students to creative thinking and learning during the implementation of advanced technologies}

Hargreaves argues that today's students must learn deep cognitive skills to foster problem solving and collaboration, i.e. the skills needed to cope with changing and new situations [11]. A systematic advanced technology training would enhance the students to do creative thinking and learning to a large extent. Because the advanced technologies represent not only new processes, new methods but also bring out new products. From the preparation of materials for carrying out the advanced processes, implementing the technologies, and achieving the new products, the students can see, can touch, can operate, and correspondingly they can feel, can learn, can think and can recollect. Several examples are shown as Fig. 2, in which the images of the typical products from the three types of advanced technologies are given.

When a student saw the medicated 3DP tablets with inner loose powders, he guessed rightly that it is for fast drug delivery. Form this and with the teachers' hints, he could list some advantages of this advanced technologies, such as flexibility (It can create parts of all kinds of geometry, and out of many kinds of material, including ceramics, metals, polymers and composites), and strong capability in creating structures (It can exercise local control over the material composition, microstructure, and surface texture).

The middle picture of Fig. 2 is a scanning electron microscope images for the comparison of the electrospun nanofibers and a human hair. Needless to say, the students showed great interesting to the fine diameters of the nanofibers, the high porosity and also the continuous threedimensional web structures. Under the hints of teachers, the students could conclude the concrete advantages of electrospun nanofibers for effective drug delivery such as 1) very large surface area-to-volume ratio; 2) a one-step top- down easy manufacturing process; 3) easy adaptation for formulation development for administration using all common routes, i.e. oral, injection, and topical applications; 4) with appropriate selection of excipients, different functional pharmaceutical ingredients may be co-distributed with the drug molecules in the composite nanofibers.

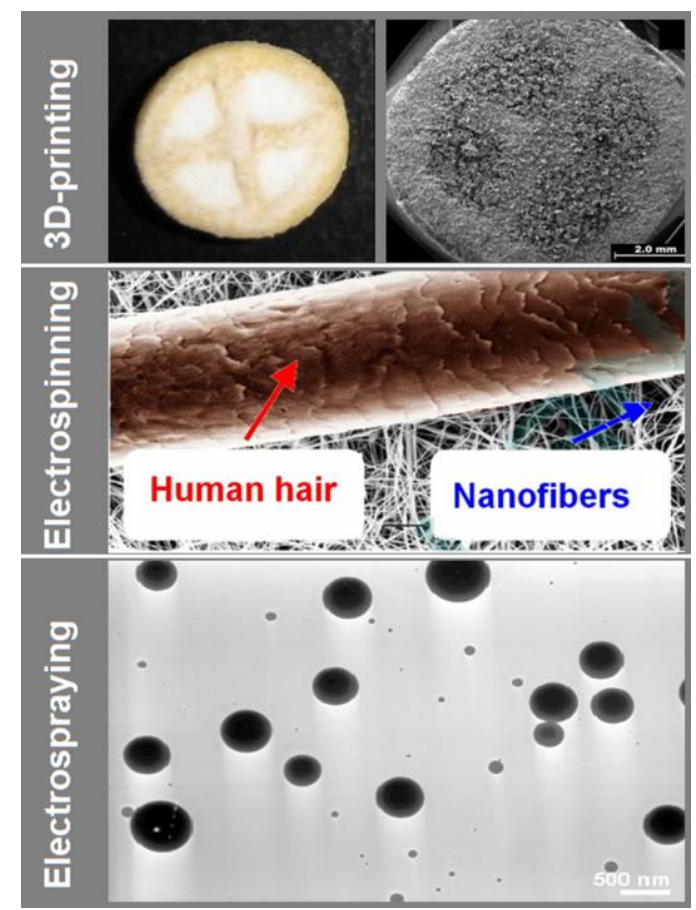

Fig. 2 Images of the products from the three types of advanced technologies

As far as the bottom picture of Fig. 2 is concerned, which is about electrosprayed core-shell nanoparticles. From this simple structure, one student intelligently asked that the two parts had an inner-outer relationship, could the electrospraying process generate nanoparticles with side-by-side relationship? This is a hot research topic today, i.e. Janus nanoparticles.

The whole process of the advanced technologies training promote the students to see, to touch, to operate, to feel, to learn, to think, to recollect and to grasp, this make them to get first-hand knowledge. And later they can certainly compare different materials, associate prior knowledge and the new experience, to analyze, to summarize and to deduce for a knowledge sublimation process.

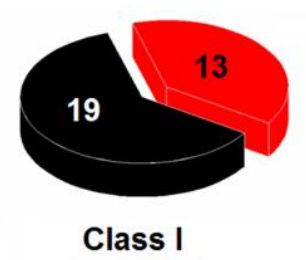

Bachelor

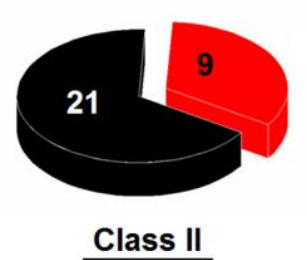

Postgraduate student
Fig. 3 The effect of education about advanced technologies on the academic interests of undergraduate students 
The innovation does not need to be something that is universally recognized as being new, but something that is new to individuals; it is about the transfer and adaptation of ideas from one context to another. It is a work at and across the boundaries of acceptability in specific contexts, it is also a capacity to connect and to do things with what has been learnt and to utilize this knowledge to learn in other situations. The advanced technology lessons can provide a lot of opportunities for training the students' ability, i.e. creativity.

For comparison, only one class was given the lessons about the training of advanced technologies in a short time period of two weeks. To our surprise, thirteen of thirty two students of this class (Class I) went a further step for scientific researches. While only nine of the thirty students of Class II went on the study for a master degree in our college who were not received the training of courses on advanced technologies previously (Fig. 3). This result suggests that the training of advanced technologies including 3D-printing, electrospinning and electrospraying have motivated the undergraduate students' interest on science and technology, drawn their attention on un-known worlds, and should foster their creativity to some extent.

\section{Conclusions}

Today too little of our teaching in higher education is focused on nurturing students' ability to think in creative ways. The educational experiences of many young people condition them to take a passive approach to the learning process. It is time to change this situation. Educational actors have the power to unlock the creative and innovative potential of the undergraduate students, for a complete picture to emerge, it will be necessary to look at the practice, pedagogy and policy concerned with creative higher education in its entirety.

Here we mainly discuss how creativity can be implemented in an engineering educational context through the training of advanced technologies. But similarly each filed has its advanced technologies, which can act as a platform for fostering undergraduate students' creativity.

We emphasize once more the importance to encourage the development of students' creative and innovative potential based on the training of advanced technologies because: 1) the upsurge of new technologies that can be exploited in creative and innovative ways and contribute to formal and informal learning; 2) the immersion in this environment lead new cohorts of students to learn and understand in different ways;
3) creativity is a form of knowledge creation, therefore stimulating creativity has positive spill over effects onto learning, supporting and enhancing self-learning, learning to learn and life-long learning skills and competences.

Certainly, the teachers themselves need to grasp several advanced technologies, develop new approaches and find new methods, solutions and practices to grab the students' attention for fostering their creativity. In the curriculum schedule of undergraduate students, the practices, particularly the access to up-to-date technologies should be increased gradually from the junior to senior grades.

\section{Acknowledgment}

This work was supported by the National Science Foundation of China (No. 51373101), the China NSFC/UK Royal Society cost share international exchanges scheme (No.51411130128), the Natural Science Foundation of Shanghai (No. 13ZR1428900) and the Key Project of the Shanghai Municipal Education Commission (No.13ZZ113).

\section{References}

[1] R.E. Ripple, "Teaching creativity," In M.A. Runco (Ed.), "Encyclopedia of Creativity," vol. 2, pp. 629-638, 1999.

[2] G.A. Anderson, "Teaching creativity for professional growth and personal reward," NACTA Journal, vol. 34, pp. 54-55, 2000.

[3] N. Behroozi, "Necessary education of creativity in high education," Edu. Eng. Iran, vol.8, pp.81-95, 2006.

[4] A.G. Tan, "Singaporean teachers' perception of activities useful for fostering creativity," J. Creat. Behav., vol. 35, pp.131-146, 2001.

[5] D.G. Yu, L.M. Zhu, C. Branford-White and X.L. Yang, "Threedimensional printing in pharmaceutics - promises and problems," $J$. Pharm. Sci.,vol. 97, pp. 3666-3690, 2008.

[6] D.G. Yu, X.X. Shen, C. Brandford-White, K. White, L.M. Zhu and S.W.A. Bligh, "Oral fast-dissolving drug delivery membranes prepared from electrospun polyvinylpyrrolidone ultrafine fibers," Nanotechnology, vol. 20, pp.055104 (1-9), 2009.

[7] C. Li, D.G. Yu, G.R. Williams and Z.H. Wang, "Fast-dissolving coreshell composite microparticles of quercetin fabricated using a coaxial electrospray process," PLOS One, vol. 9, pp. 92106, 2014.

[8] M. Scardamalia, "Big change questions "Will educational institutions, within their present structures, be able to adapt sufficiently to meet the needs of the information age?" J. Edu. Change, vol.2, pp.171-176, 2001

[9] C. McGloughlin and M. J. W. Lee, "Personalised and self regulated learning in the Web 2.0 era: International exemplars of innovative pedagogy using social software," Austr. J. Edu. Technol., vol.26, pp.2843, 2010

[10] D. Kees and C. Nigel, "Creativity in the design process: co-evolution of problem-solution," Design Stud., vol. 22, pp. 425-437, 2001.

[11] P. Sahlberg, "Rethinking accountability in a knowledge society," J. Edu. Change, vol. 11, pp. 45-61, 2010. 